\title{
RELAÇÃO DE UNIDADES DE AGRICULTURA FAMILIAR DA COSTA OESTE PARANAENSE COM O NOVO RURAL BRASILEIRO
}

\author{
RELATIONSHIP OF FAMILY AGRICULTURE UNITS IN THE COSTA OESTE \\ PARANAENSE WITH THE NEW BRAZILIAN RURAL
}

\author{
RELACIÓN DE UNIDADES DE AGRICULTURA FAMILIAR DE LA COSTA \\ OESTE DE PARANAENSE CON EL NUEVO RURAL BRASILEÑO
}

\author{
Valdir Serafim Junior ${ }^{1}$ \\ https://orcid.org/0000-0002-7494-8131 \\ Adriana Maria de Grandi ${ }^{2}$ \\ https://orcid.org/0000-0002-5917-0536 \\ Fabíola Graciele Besen ${ }^{3}$ \\ https://orcid.org/0000-0002-8740-2920 \\ Sandra Maria Coltre \\ https://orcid.org/0000-0001-6699-0500
}

Submetido: 04/05/2021 / Aceito: 12/07/2021 / Publicado: 04/02/2022.

\begin{abstract}
Resumo
A agricultura familiar tem grande importância no crescimento do país e para a segurança alimentar, porém, com as mudanças sofridas pelo meio rural nas últimas décadas, ela vem sofrendo transformações em vários aspectos. O objetivo do estudo é identificar as características de unidades familiares localizadas na região da Costa Oeste do Paraná, em relação aos membros residentes e suas relações com o novo rural brasileiro. Esta pesquisa caracteriza-se como um estudo descritivo, com abordagem quantitativa e fontes secundárias extraídas do banco de dados dos relatórios do "Projeto de Agricultura Orgânica na BP3", trabalho conduzido e desenvolvido pela Biolabore - Cooperativa de Trabalho e Assistência Técnica do Paraná, em conjunto com a Itaipu Binacional. As informações foram extraídas dos relatórios de 200 unidades de agricultura familiar. Identificou-se a ocorrência de pequenas famílias, em média com 3 membros residentes e parcela considerável de unidades onde somente residem o casal. Com relação a faixa etária, verificou-se que os membros residentes estão concentrados entre as faixas de 30 a 59 anos com 49,3\%, e uma significativa presença de jovens até 19 anos $(25,3 \%)$ e membros mais idosos com idade

\footnotetext{
${ }^{1}$ Bacharel em Ciências Contábeis. Mestre em Extensão Inovadora e Desenvolvimento Rural Sustentável. Doutor em Desenvolvimento Rural Sustentável pela Universidade Estadual do Oeste do Paraná (Unioeste). Professor do Curso de Ciências Contábeis da Unioeste Campus de Foz do Iguaçu. E-mail: jr_valdir@hotmail.com

${ }^{2}$ Professora associada a no curso de agronomia na Universidade Estadual do Oeste do Paraná - Unioeste - Paraná - Brasil Graduação: Engenharia Agrícola - Universidade Estadual do Oeste do Paraná - Unioeste - 1996, Mestrado: Engenharia Agrícola - Universidade Federal de Viçosa - UFV - 1999 Doutorado: Engenharia Agrícola - Universidade Federal de Viçosa - UFV - 2003. E-mail: adrianadegrandi@gmail.com

${ }^{3}$ Bacharel em Ciências Contábeis. Mestre em Extensão Inovadora e Desenvolvimento Rural Sustentável. Doutora em Desenvolvimento Rural Sustentável pela Universidade Estadual do Oeste do Paraná (Unioeste). Professora do Curso de Ciências Contábeis da Unioeste Campus de Foz do Iguaçu. E-mail: fabiolagracielebesen@ gmail.com

${ }^{4}$ Bacharel em Administração. Mestre em Engenharia da produção. Doutora em Engenharia da Produção pela Universidade Federal de Santa Catarina (UFSC). Professora do Curso de Administração da Universidade Estadual do Oeste do Paraná (Unioeste) - Campus de Foz do Iguaçu. E-mail: sandracutu@gmail.com
} 
superior a 60 anos (7,5\%). A taxa de analfabetismo é considerada baixa, porém com grande concentração de membros com ensino fundamental incompleto nas faixas etárias mais elevadas, indicando atraso educacional dos mais velhos e a formação educacional mais elevada está relacionada aos mais novos. Identificou-se que os membros residentes mais velhos são casados e dedicam mais tempo e mão de obra a propriedade, os mais jovens são solteiros, podendo constituir vínculo familiar fora do eixo rural, dedicando menos tempo as atividades agrícolas. Existe homogeneidade de variâncias entres as médias de idade e dias dedicados a propriedade entre os homens e as mulheres e indícios de pluriatividade nas unidades estudadas. Constatou-se que $65,9 \%$ dos membros residentes não possuem renda extra agrícola, entre os membros com este tipo de renda, $(20,4 \%)$ a fonte advinda de aposentadorias é a principal, seguida pelas diversas outras funções desempenhadas pelos agricultores fora de sua propriedade que lhes rendem remuneração e $26,7 \%$ concentram-se na faixa entre 1 e 2 salários-mínimos que contribuem para a ampliação da renda familiar. Como trabalhos futuros, sugere-se o levantamento das potencialidades locais para a identificação de oportunidades e renda.

Palavras - chave: Aspectos sociais, organização familiar, transformação.

\begin{abstract}
Family farming is of great importance for the country's growth and for food security, however, with the changes undergone by the rural environment in recent decades, it has undergone transformations in several aspects. The aim of the study is to identify the characteristics of family units located in the West Coast of Paraná, in relation to resident members and their relationship with the new rural Brazilian. This research is characterized as a descriptive study, with a quantitative approach and secondary sources extracted from the database of the reports of the "Project for Organic Agriculture in BP3", work conducted and developed by Biolabore - Cooperative of Work and Technical Assistance of Paraná, in together with Itaipu Binacional. The information was extracted from the reports of 200 family farming units. The occurrence of small families was identified, with an average of 3 resident members and a considerable portion of units where only the couple live. Regarding the age group, it was found that the resident members are concentrated between the age groups of 30 to 59 years old with $49.3 \%$, and a significant presence of young people up to 19 years old $(25.3 \%)$ and older members aged older than 60 years $(7.5 \%)$. The illiteracy rate is considered low, but with a high concentration of members with incomplete primary education in older age groups, indicating educational delay of older people and higher educational background is related to younger people. It was identified that the older resident members are married and devote more time and labor to the property, the younger members are single, which can form a family link outside the rural axis, dedicating less time to agricultural activities. There is homogeneity of variances between the average age and days devoted to property between men and women and evidence of pluriactivity in the units studied. It was found that $65,9 \%$ of resident members do not have extra-agricultural income, among members with this type of income, (20.4\%) the source of pensions is the main source, followed by the various other functions performed by farmers abroad. of their property that earn them remuneration and $26,7 \%$ are concentrated in the range between 1 and 2 minimum wages that contribute to the expansion of family income. As future work, the survey of local potentials for identifying opportunities and income is suggested.
\end{abstract}

Keywords: Social aspects, family organization, transformation. 


\section{Resumen:}

La agricultura familiar es de gran importancia para el crecimiento del país y para la seguridad alimentaria, sin embargo, con los cambios que ha sufrido el medio rural en las últimas décadas, ha sufrido cambios en varios aspectos. El objetivo del estudio es identificar las características de las unidades familiares ubicadas en la Costa Oeste de Paraná, en relación a los miembros residentes y su relación con el nuevo rural brasileño. Esta investigación se caracteriza por ser un estudio descriptivo, con enfoque cuantitativo y fuentes secundarias extraídas de la base de datos de los informes del "Proyecto de Agricultura Orgánica en BP3", trabajo realizado y desarrollado por Biolabore - Cooperativa de Trabajo y Asistencia Técnica de Paraná, en junto con Itaipu Binacional. La información se extrajo de los informes de 200 unidades de agricultura familiar. Se identificó la ocurrencia de familias pequeñas, con un promedio de 3 miembros residentes y una porción considerable de unidades donde vive solo la pareja. En cuanto al grupo de edad, se encontró que los miembros residentes se concentran entre los grupos de edad de 30 a 59 años con un $49,3 \%$, y una presencia significativa de jóvenes hasta los 19 años $(25,3 \%)$ y miembros mayores de 60 años $(7,5 \%)$. La tasa de analfabetismo se considera baja, pero con una gran concentración de afiliados con educación primaria incompleta en los grupos de mayor edad, lo que indica un retraso educativo de las personas mayores y la formación académica superior se relaciona con los más jóvenes. Se identificó que los residentes mayores están casados y dedican más tiempo y trabajo a la propiedad, los miembros más jóvenes son solteros, lo que puede formar un vínculo familiar fuera del eje rural, dedicando menos tiempo a las actividades agrícolas. Existe homogeneidad de varianzas entre la edad promedio y los días dedicados a la propiedad entre hombres y mujeres y evidencia de pluriactividad en las unidades estudiadas. Se encontró que el 65,9\% de los afiliados residentes no tienen ingresos extraagrícolas, entre los afiliados con este tipo de ingresos, $(20,4 \%)$ la fuente de pensiones es la fuente principal, seguida de las diversas otras funciones que realizan los agricultores en el exterior. sus propiedades que les devengan una remuneración y el 26,7\% se concentran en el rango entre 1 y 2 salarios mínimos que contribuyen a la expansión del ingreso familiar. Como trabajo futuro, sugerimos la encuesta de potencial local para identificar oportunidades e ingresos.

Palabras clave: Aspectos sociales, organización familiar, transformación.

\section{INTRODUÇÃO}

Existem diversos estudos relacionados à agricultura familiar e seus sujeitos, destacando, principalmente a importância do seu lugar no crescimento do país e segurança alimentar, bem como as mudanças sofridas pelo meio rural nas últimas décadas.

Para Camargo e Oliveira (2012), ainda que a categoria denominada novas ruralidades não se empregue no Brasil como em moldes europeus, por aqui não se pode negar que haja transformações que incluem novas atividades e outras categorias sociais, além da agricultura e dos agricultores. Em várias regiões brasileiras, a agricultura continua sendo o fator base de desenvolvimento local e do tipo de ruralidade encontrada, com suas relações sociais, meio ambiente, com capacidade de reproduzir a paisagem cultural e ambiental atraente tanto para os que moram no campo, bem como aos que procuram melhor qualidade de vida.

"O espaço rural não mais pode ser pensado apenas como um lugar produtor de mercadorias agrárias e ofertador de mão-de-obra. Além dele poder oferecer ar, água, 
turismo, lazer, bens de saúde, possibilitando uma gestão multipropósito do espaço rural, oferece a possibilidade de, no espaço local-regional, combinar postos de trabalho com pequenas e médias empresas" (GRAZIANO DA SILVA, 1997, p. 25).

Para a manutenção e desenvolvimento deste potencial existe a necessidade de manter os seus elementos constitutivos, garantindo acesso à terra a uma ampla série de produtores familiares inclusos em diversos sistemas produtivos, com facilidade de crédito e garantia de mercado dos produtos com preços compensatórios. Dessa forma, a agricultura familiar poderá desempenhar suas múltiplas funções para a garantia de um rural em movimento de transformação e de integração de uma diversidade de atores e interesses (CAMARGO e OLIVEIRA, 2012).

O Brasil tem vivenciado nos últimos anos avanços importantes a respeito das definições e compreensões de características e do significado do grupo social denominado agricultura familiar, dentre eles a sua grande diversidade econômica e heterogeneidade social, constituídos por pequenos proprietários de terra, que se utilizam da mão de obra da família para a força de trabalho, produzindo tanto para o seu auto consumo como para a comercialização e vivendo em pequenas comunidades ou povoados rurais (SCHNEIDER e CASSOL, 2014).

Conforme o estudo coordenado por Hugues Lamarche (1998), que contou com a participação de renomados pesquisadores brasileiros como Nazareth Wanderley, Anita Brumer, Fernando Lourenço e Ghislaine Duque, identificou-se que os elementos comuns na diversidade de situações encontradas na Europa e no Brasil, é o caráter familiar do trabalho, da gestão e da posse da terra, e que não faz sentido resumir a diversidade da agricultura familiar às condições que mais se aproximam da ideia clássica de campesinato, como defendem alguns autores (ABRAMOVAY, 2012).

A partir destas considerações, torna-se importante os estudos sobre os agricultores e seus membros familiares com as novas características apresentadas pelo rural brasileiro. Desse modo o presente estudo tem como questão de pesquisa: Quais são as características sociais de unidades de agricultura familiar na Costa Oeste Paranaense e sua relação com a nova ruralidade?

Este capítulo está estruturado em cinco seções, sendo esta, a primeira, em que consta o problema, objetivo, justificativa e estrutura da pesquisa. Em seguida, na segunda seção, são apresentados os conceitos relacionados à Agricultura Familiar, Agricultores Familiares e O novo Rural Brasileiro; na terceira, é destacada a metodologia utilizada; na quarta, são expostos os resultados do estudo; e por fim, na última seção, apresenta-se as considerações finais, além das referências bibliográficas.

\section{REFERENCIAL TEÓRICO}

\section{Agricultura familiar}

O conceito de agricultura familiar é um conceito em construção, mas há necessidade de discussão sobre o mesmo, para diferenciá-lo do conceito de campesinato, utilizado por alguns estudiosos do mundo rural. Abramovay (2012, p.142), afirma ser necessária essa diferenciação, pois "tanto a venda das safras como a compra dos insumos passam por uma integração parcial a mercados incompletos", no caso do campesinato, apontando que há uma diferença de natureza social entre o campesinato e a agricultura familiar. 
Para Lênin (1969), sob um viés marxista, o camponês seria extinto pela dinâmica da diferenciação entre os produtores, pois como produtor de mercadorias, ele optaria por uma das duas classes fundamentais da sociedade: o proletariado ou a burguesia. Kautsky (1980), acreditava que a agricultura ao aderir ao processo de modernização, retiraria o pequeno agricultor de cena, já que ele não conseguiria incorporar essas tecnologias e não resistiria a concorrência das grandes empresas agrícolas (ABRAMOVAY, 2012).

Marx (1818 - 1883), não se dedicou a estudar a produção familiar na agricultura [...] o desenvolvimento econômico distribui funções entre diferentes pessoas; e o artesão ou o camponês que produz com seus próprios meios de produção ou será transformado gradualmente num pequeno capitalista que também explora o trabalho alheio ou sofrerá a perda de seus meios de produção e será transformado em trabalhador assalariado (MARX, apud DE JANVRY, 1981).

Alexander Chayanov (1888-1930), e posterior a ele o polonês Jerzy Tepich (1973), buscaram identificar "uma definição de campesinato cuja base seria a própria família, e as determinações que a estrutura familiar impõe sobre o comportamento econômico" (ABRAMOVAY, 2012, p.34). Para Chayanov, o campesinato é um segmento que tem o trabalho e o consumo como fatores determinantes das decisões econômicas, e o "sistema econômico camponês pode se desenvolver nas mais diferentes organizações sociais (ABRAMOVAY, 2012).

Para Abramovay (2012), o agricultor familiar ao se integrar ao mercado econômico, perde seu caráter camponês, pois o camponês se insere de forma parcial aos mercados incompletos, tem uma cultura tradicional e um modo de vida de pequenas comunidades rurais, baseado em uma ética de subsistência e reciprocidade. $\mathrm{O}$ agricultor familiar tem maior integração ao mercado, embora permaneça a forma de produção baseada na família.

Pela legislação o conceito é bem mais enxuto, pois segundo a Lei de Agricultura Familiar (Lei 11.326/2006), agricultor familiar é:

\footnotetext{
[...] aquele que pratica atividades no meio rural, atendendo simultaneamente, aos seguintes requisitos: I não detenha, a qualquer título, área maior do que 4 (quatro) módulos fiscais; II utilize predominantemente mão de obra da própria família nas atividades econômicas do seu estabelecimento ou empreendimento; III tenha renda familiar predominantemente originada de atividades econômicas vinculadas ao próprio estabelecimento ou empreendimento; IV dirija seu estabelecimento ou empreendimento com sua família (BRASIL, 2006).
}

Para Grisa e Schneider (2015), a conceituação de agricultura familiar está caracterizada por uma produção que é orientada para o mercado, mas também para a para a subsistência da família, utilizando predominantemente mão de obra familiar, bem como são possuidores da terra e dos meios de produção, diferenciando-se da agricultura empresarial que possui uma produção totalmente orientada para o mercado, é altamente mecanizada e contrata mão de obra assalariada.

As características de relação com o mercado em alguns estilos de agricultura, estão relacionados a um processo de inserção no regime de produção voltado ao capitalismo, aparecem como uma forma empresarial de agricultura familiar, dependendo de certas especializações produtivas, uso de recursos externos e dos custos de produção e transação. Porém, também existem estilos que se distanciam de certos modelos dominantes, criam diferentes formas de diversificar os circuitos de troca e buscam por autonomia em relação 
às obrigações das formas impostas pelos agentes externos de modelos agrícolas dominantes (SCHNEIDER, 2010).

Segundo Wanderley (2003), é pertinente o conceito de agricultura e agricultor familiar para compreender o ator a que se refere, e mesmo que essa identidade tenha sido atribuída na maioria dos casos, ela é incorporada pelos próprios agricultores e aponta qualidades positivas na sua tipologia dentro de seu processo de desenvolvimento, indicando que o agricultor familiar não é passivo contra as forças dominantes externas e internas do seu universo e tem poder de construir sua própria história no meio rural inserido na sociedade moderna.

A região Costa Oeste do Paraná, foco do presente estudo, apresenta características peculiares, primeiramente pela sua localização geográfica, na tríplice fronteira: Brasil, Paraguai e Argentina e por estar entre eixos de desenvolvimento econômico importantes entre as cidades de Foz do Iguaçu, Cascavel e Toledo. Outra característica não menos importante, são os impactos gerados pela construção da Hidrelétrica de Itaipu e a formação de seu reservatório, fato este que redesenhou geográfica e economicamente os municípios atingidos.

A mesorregião Oeste, dentre as regiões do Estado, é talvez aquela na qual melhor se visualiza o processo de desenvolvimento tecnológico na produção agropecuária. A constituição dos segmentos industriais, principalmente a jusante do setor e através de organizações de cooperativas, bem como a importância das exportações primárias, definiram a dinâmica da economia regional e sua articulação às economias estadual, nacional e mundial (IPARDES, 2004.).

As áreas com maior aptidão à agricultura correspondem a $75 \%$ da região Oeste áreas de relevo plano e suavemente ondulado com predomínio de solos férteis e com pouca susceptibilidade à erosão associados às baixas declividades dos terrenos. Tais solos, ocupados principalmente por culturas cíclicas, proporcionam práticas agrícolas com alto nível tecnológico, aplicação intensiva de insumos, melhoramento das condições da lavoura e motomecanização, principalmente nos municípios de Guaíra, Palotina, Marechal Cândido Rondon, Toledo e Cascavel (IPARDES, 2004).

O próximo tópico aborda esse ator da agricultura familiar e suas características, e como afirma Schneider (2003), a incorporação e afirmação da noção de agricultura familiar passou a atuar como um guarda-chuva as diversas denominações: assentados, arrendatários, parceiros, integrados a agroindústrias, que não mais podiam ser confortavelmente identificados com as noções de pequenos produtores, ou simplesmente, de trabalhadores rurais".

\section{Os agricultores familiares}

$\mathrm{Na}$ atualidade existem confrontos concentrados entre a grande propriedade e outras formas sociais de produção, sendo uma delas a agricultura familiar, mas estes confrontos se dão num contexto sob muitos aspectos positivos, como a reconstrução democrática brasileira que estimulou a organização dos agricultores e possibilitou o livre debate nas instituições; criação de políticas públicas, como exemplo o PRONAF $^{5}$, legitimando o

\footnotetext{
${ }^{5}$ O PRONAF (Programa Nacional de Fortalecimento da Agricultura Familiar é um programa do Governo Federal que tem como objetivo fortalecer a agricultura familiar por meio do financiamento subsidiado de serviços agropecuários e não agropecuários (EMBRAPA, 2020).
} 
protagonismo do agricultor familiar; a profunda crítica ao modelo produtivista de modernização agrícola; o avanço da ciência e novas técnicas produtivas alternativas ao modelo da Revolução Verde e a globalização, no ponto de vista da ampliação de horizontes e espaços de intercâmbio destes agricultores (WANDERLEY, 2009).

Segundo Buainain (2006), os agricultores familiares diversificam-se historicamente pela formação de grupos, heranças culturais, experiência profissional e de vida particulares, acesso e disponibilidade diferenciada de um conjunto de fatores, entre eles os recursos naturais, capital humano e social; distinguem-se pela inserção de grupos em paisagens agrárias bem diferentes umas das outras; acesso diferenciado a mercados e inserção socioeconômica dos produtores, resultantes das condições particulares dos diversos grupos e oportunidades geradas pelo movimento da economia ou de políticas públicas.

Schneider e Cassol (2014), sintetizaram a classificação do agricultor familiar em três grupos: um grupo predominante de estabelecimentos especializados, dependentes da receita da atividade agropecuária, principalmente vegetal, com certa abertura para atividades fora do estabelecimento, porém, com vocação e estratégia de reprodução social pela agropecuária. $\mathrm{O}$ segundo, um grupo pequeno de estabelecimentos com várias fontes de ingresso de receita, não sendo a receita agrícola única, nem mesmo a mais importante, onde entradas de atividades não agrícolas e aposentadorias são consideráveis, suas estratégias de reprodução não passam pela produção, não acessam serviços de extensão e possuem pouca área para ampliação da agricultura. E o terceiro grupo que vive no espaço rural, mas não é expressivo o sentido econômico de sua atividade agrícola ou agropecuária, a propriedade passa a ser um lugar de residência e a produção é voltada ao autoconsumo.

Os agricultores familiares fazem parte desse universo diferenciado, a composição de seus grupos está relacionada a interesses particulares, estratégias próprias de sobrevivência e de produção, reagindo de maneira diferente aos desafios, oportunidades e restrições similares, necessitando de um tratamento compatível com as diferenças. Reconhecer essa diferenciação é o núcleo de pensamento sobre o desenvolvimento da agricultura familiar de maneira geral e sobre a potencialidade de introdução da agricultura alternativa como estratégia de desenvolvimento (BUAINAIN, 2006).

Para Delgado e Bergamasco (2017) as normas invisíveis de trabalho e a produção do que se pode chamar de "riqueza invisível" é uma das particularidades da Agricultura Familiar, suprimida das sínteses econômicas. A família é uma instituição estratégica do meio rural e responsável pela concepção de atores do desenvolvimento rural, seja relacionado a mão de obra qualificada ou por trabalhadores sem qualificação, trabalhadores sazonais e migrantes em todas as regiões do país, demonstrando que dentro da unidade doméstica concentram-se esforços reprodutivos onde participam sobretudo mulheres, crianças e idosos.

\section{O novo rural brasileiro}

No Brasil, atualmente, passou a identificar-se uma nova configuração do mundo rural, e essa transformação se dá pela ocupação das pessoas residentes no campo, onde as tarefas agrícolas vêm sofrendo uma facilitação devido ao progresso técnico nas atividades agropecuárias, poupando mão de obra. Em contrapartida, nascem novas atividades agrícolas no meio rural em especializações de mercado e oportunidades de atividades não 
agrícolas, seja no centro urbano mais próximo ou no próprio meio rural, compensando a queda dos ocupados na agricultura (BUAINAIN e SALVADORI, 2009).

Entre 1970 e 2010, a participação da população rural caiu de $44 \%$ para $15,6 \%$, e enquanto a população urbana cresceu $2,5 \%$ ao ano, nos anos 90 , e $1,6 \%$ nos anos 2000 , e a população rural passou de 35,7 milhões de pessoas em 1991 para 29,7 milhões em 2010, queda de 1,0\% ao ano. Essa dinâmica demográfica das populações urbanas e rurais entre 1991 e 2010 indica a continuidade da tendência de esvaziamento demográfico rural no Brasil, mesmo que em ritmo mais ameno na última década (MAIA e BUAINAIN, 2015, PNAD, 2015).

Essa mobilização da população para a área urbana decorreu, em parte, pelo sistema de mecanização empregado para produção agrícola em larga escala no decorrer dos anos. $\mathrm{O}$ movimento de forte migração das áreas rurais para as cidades, determinou o crescimento desordenado de grandes aglomerações e a formação de centros metropolitanos, que são reflexos dessa dinâmica (PEREHOUSKEI, JACINTO e MENDES, 2012, MARQUES, 2014).

Além do êxodo em função da mecanização empregada na agricultura, para Sacco dos Anjos e Caldas (2003), as transformações incidentes no meio rural estão relacionadas a três grandes processos, a masculinização, o envelhecimento e a desagrariação. A masculinização e o envelhecimento resultam do efeito de um êxodo rural seletivo exercido nas duas últimas décadas no campo, enviando as cidades a mão de obra jovem e preferencialmente feminina, podendo comprometer a longo prazo a renovação da força de trabalho rural, enquanto o envelhecimento é consequência do aumento da esperança de vida da população rural, em conjunto com a diminuição absoluta e relativa da participação da população jovem. O envelhecimento da população no Brasil, faz parte dos estudos acadêmicos e das políticas públicas, diante do aumento significativo no índice de envelhecimento, que era de 7,32\% da população em 2010 e está em 10,15\% em 2021. Até 2060, representará 25,49\% da população (IBGE, 2021). Em 2006, quando foi realizado o último censo rural, as pessoas com mais 65 anos representavam 17,52\% da população do campo. Hoje, esse grupo gira em torno de 21,4\% (IBGE, 2006, 2019).

Quanto a desagrariação, esta representa a competência decrescente da agricultura no sentido de ocupação da população economicamente ativa no campo brasileiro, haja vista o aumento de pessoas o número de pessoas absorvidas em atividades extra agrícolas (ANJOS e CALDAS, 2003).

Segundo Alentejano (2015), existem elementos que indicam perspectiva de criação de um novo modelo de desenvolvimento no campo brasileiro, onde destacam-se processos de valorização da agricultura familiar, avanço da pluriatividade, difusão de novas práticas agrícolas ambientalmente mais saudáveis, resultado de múltiplos assentamentos rurais no país e do avanço da regularização fundiária, porém, há grandes evidências no sentido oposto, a persistência da concentração fundiária, do êxodo rural, do domínio do grande capital agroindustrial no campo e do empobrecimento dos agricultores familiares.

Com essas transformações significativas que vem ocorrendo no meio rural brasileiro, em função da modernização da agricultura e do desenvolvimento dos centros urbanos, a agropecuária moderna e a agricultura de subsistência passaram a dividir espaço com um conjunto de atividades ligadas ao comércio, serviços e indústria, reduzindo cada vez mais, as diferenças entre o rural e o urbano (TELLES, COSTA, BACCHI e LAURENTI, 2017).

O Projeto Rurbano, denominado "Caracterização do Novo Rural Brasileiro", que teve início em 1997, teve como objetivo investigar a dinâmica do emprego agrícola nas 
áreas rurais do território nacional. A partir desse estudo, pode-se verificar a interrupção da redução do tamanho e a crescente diversificação ocupacional da população rural (GRAZIANO DA SILVA, 2001; GRAZIANO DA SILVA; DEL GROSSI, 2001; LAURENTI, 2014 apud TELLES, COSTA, BACCHI e LAURENTI, 2017).

A dinâmica do espaço rural não pode ser compreendida somente pelos estudos das atividades agropecuárias, pois ocorreu um avanço no uso deste espaço com o surgimento de novas competências, surgindo um novo olhar sobre o rural e uma redefinição de suas atribuições. $\mathrm{O}$ conceito de espaço rural vem sendo redefinido, devido ao aparecimento de novas funções e novos tipos de ocupações nele inseridas, não somente relacionadas a produção, mas também pela atração exercida cada vez mais na população urbana, criando um processo de valorização do campo pelo urbano, associando o rural a natureza, à saúde, à liberdade, descanso, qualidade de vida e outros (ELESBÃO, 2007).

\section{METODOLOGIA}

Esta pesquisa caracteriza-se como um estudo exploratório, descritivo e analítico, com fontes apenas secundárias, extraídas dos relatórios do "Projeto de Agricultura Orgânica na BP3", trabalho conduzido e desenvolvido pela Biolabore - Cooperativa de Trabalho e Assistência Técnica do Paraná, em conjunto com a Itaipu Binacional.

A BP3 - Bacia do Paraná 3, está localizada no extremo Oeste do Paraná, onde foram atendidos pela Biolabore, através de ATER - Assistência Técnica e Extensão Rural, durante o período de 04/2015 a 04/2018, através do Projeto Desenvolvimento Rural Sustentável - Programa Cultivando Água Boa da Itaipu Binacional, atendendo 535 unidades de agricultura familiar com potencialidade agroecológica em vários municípios da região, representando a população da pesquisa.

Para a amostra do estudo, fizeram parte 200 unidades de agricultura familiar distribuídas nos municípios de Diamante do Oeste, Entre Rios do Oeste, Guaíra, Medianeira, Pato Bragado, Santa Helena, São José das Palmeiras e Terra Roxa, localizados na BP3, na Costa Oeste do Paraná, esse agrupamento apresenta proximidade geográfica, características climáticas, tipos de solo similares e semelhanças nos sistemas produtivos, contemplando 599 membros residentes nestas unidades, os quais fazem parte da análise. Segundo a Águas Paraná (2014) não há distinções significativas de solo e clima na região estudada, conforme demonstrado no relatório 'Plano da Bacia Hidrográfica do Paraná 3 Características gerais da bacia', realizado em conjunto pela Unioeste, Itaipu, Águas Paraná e Comitê da Bacia Hidrográfica do Paraná 3, assim optou-se por esta amostra aleatória.

Os resultados apresentaram 95\% de confiança numa margem de erro de 5,5\%, conforme a Fórmula 1 como base para cálculo amostral, onde $\mathbf{n}$ é a amostra calculada, $\mathbf{N}$ é a população, $\mathbf{Z}$ a variável normalmente padronizada associada ao nível de confiança, $\mathbf{p}$ a verdadeira probabilidade do evento e o erro amostral.

$$
n=\frac{\mathrm{N} \cdot Z^{2} \cdot p \cdot(1-p)}{Z^{2} \cdot p \cdot(1-p)+e^{2} \cdot(N-1)}
$$

Os dados foram analisados com recursos matemáticos para a descrição das causas e relações entre as variáveis, em seguida, foram inseridos em software de gerenciamento estatístico próprio para proceder suas análises quantitativas. 


\section{RESULTADOS E DISCUSSÕES}

Para compreender o funcionamento das unidades familiares estudadas nestes municípios na Costa Oeste do Paraná, inicialmente foram levantados os dados da composição familiar, identificando-se, conforme a Tabela 16 que existe a predominância de famílias com apenas dois membros residentes e que, em média, as famílias apresentam 3 membros residentes, chamando a atenção para algumas unidades em que existe somente um membro residente.

Levando em consideração que na agricultura familiar a força de trabalho no estabelecimento é realizada pelos membros da família, estes estabelecimentos que apresentam poucos membros residentes podem apresentar necessidade de contratação de mão de obra externa, optar por atividades que não necessitem de níveis altos de mão de obra empregada ou mesmo atividades que apresentem alto nível de automação (BUAINAIN, 2006).

A falta de mão de obra familiar bloqueia a adoção de sistemas de produção potencialmente mais rentáveis, principalmente em produtores menos capitalizados sem condições de contratação de mão de obra assalariada em momentos de pico. Outro aspecto é a falta de alternativas locais para a reprodução dos membros destas famílias, levando a um processo de migração, o que aumenta a falta de mão de obra e em várias áreas já se constata o envelhecimento e o celibato no meio rural (BUAINAIN, 2006).

A importância do êxodo rural é confirmada quando se examinam os dados dos últimos 50 anos: desde 1950, a cada 10 anos, um em cada três brasileiros vivendo no meio rural opta pela migração, e atualmente a população rural representa $15 \%$ da população total brasileira (CAMARANO e ABRAMOVAY, 1999, IBGE, 2019).

Tabela 1 - Quantidade de membros residentes das unidades familiares

\begin{tabular}{lcc}
\hline Membros residentes & Frequência & \% \\
\hline 2 membros & 78 & 39,0 \\
3 membros & 49 & 24,5 \\
4 membros & 35 & 17,5 \\
5 membros & 22 & 11,0 \\
1 membro & 10 & 5,0 \\
6 membros & 6 & 3,0 \\
\hline Total & $\mathbf{2 0 0}$ & $\mathbf{1 0 0 , 0}$ \\
\hline \hline Média & 3 & membros \\
Moda & 2 & membros \\
\hline \hline
\end{tabular}

Fonte: Dados da pesquisa (2020).

Contribuindo com a primeira análise, aponta-se na Tabela 1 a descrição do vínculo familiar desses membros residentes, onde a predominância encontra-se na residência do casal, esposo e esposa, com $61,20 \%$ do total dos membros, seguido pelos filhos com $33,5 \%, 1,5 \%$ declaram-se como proprietários pessoas solteiras, divorciadas e viúvas que residem sozinhas na propriedade, e com menos amplitude aparecerem a presença de avós ou somente a presença individual do pai ou da mãe nessas unidades.

Com relação a faixa etária, verificou-se que os membros residentes estão concentrados entre as faixas de 30 a 59 anos com 49,3\%, e uma significativa presença de jovens até 19 anos $(25,3 \%)$ e membros mais idosos com idade superior a 60 anos (7,5\%). O que chama atenção nesse grupo é a pouca concentração de membros na faixa de 20 a 29 anos, com somente $8 \%$, necessitando de uma análise sobre os fatores de permanência destes jovens na área rural. 
Mesmo considerando as várias dimensões do meio rural, pode-se refletir preliminarmente, em alguns pontos de acordo com a pesquisa de Dotto (2011), no Estado do Mato Grosso do Sul, indicando que atualmente o rural confunde e difunde sua realidade com a cidade, onde os jovens buscam novas relações para atender necessidades específicas, principalmente quando existe proximidade e mobilidade fácil entre rural e urbano. A busca por educação, aspectos culturais das famílias, seu poder econômico e segurança financeira e busca de independência e garantias não conseguidas na agricultura familiar, estão entre as justificativas apontadas para a saída do campo. Segundo Buainaim et al. (2013), a hipótese é que a decisão de migrar esteja mais associada às assimetrias estruturais entre a qualidade de vida nas áreas urbanas e rurais. Assim, há a necessidade de aprofundar o conhecimento das condições de vida e do potencial de desenvolvimento embutido, hoje, no meio rural, a fim de entender essa saída dos jovens.

Tabela 2 - Características dos membros residentes das unidades familiares

\begin{tabular}{lcc|lcc}
\hline \hline Vinculo familiar & Frequência & \% & Sexo & Frequência & \% \\
\hline Esposo & 183 & $30,6 \%$ & Masculino & 309 & $51,6 \%$ \\
Esposa & 183 & $30,6 \%$ & Feminino & 290 & $48,4 \%$ \\
Filho & 111 & $18,5 \%$ & Total & Frequência & $\mathbf{1 0 0 , 0 \%}$ \\
\cline { 5 - 6 } Filha & 90 & $15,0 \%$ & Faixa etária & 80 & $13,4 \%$ \\
\cline { 4 - 6 } Somente o(a) proprietário(a) & 9 & $1,5 \%$ & Menor que 14 anos & 71 & $11,9 \%$ \\
Avó & 7 & $1,2 \%$ & Entre 14 a 19 anos & 48 & $8,0 \%$ \\
Mãe & 5 & $0,8 \%$ & Entre 20 a 29 anos & 67 & $11,2 \%$ \\
Pai & 3 & $0,5 \%$ & Entre 30 a 39 anos & 106 & $17,7 \%$ \\
Avô & 3 & $0,5 \%$ & Entre 40 a 49 anos & 122 & $20,4 \%$ \\
Enteado (a) & 2 & $0,3 \%$ & Entre 50 a 59 anos & 73 & $12,2 \%$ \\
Neto (a) & 2 & $0,3 \%$ & Entre 60 a 69 anos & 32 & $5,3 \%$ \\
Nora & 1 & $0,2 \%$ & Maior ou igual a 70 anos & $\mathbf{5 9 9}$ & $\mathbf{1 0 0 , 0 \%}$ \\
\hline Total & $\mathbf{5 9 9}$ & $\mathbf{1 0 0 \%}$ & Total & &
\end{tabular}

Fonte: Dados da pesquisa (2020).

Quanto à questão de gênero, verificou-se uma paridade entre homens e mulheres residentes nas unidades estudadas, essa equidade é reflexo dos dados verificados no vínculo familiar, onde a base está concentrada no casal e seus filhos, apontando resultados opostos a pesquisas que indicam uma grande migração do excedente feminino para centros urbanos. Em 1950, havia mais moças que rapazes ${ }^{6}$ no meio rural brasileiro. Em 1960, a proporção entre os sexos era praticamente a mesma, mas a cada década o predomínio populacional dos rapazes foi aumentando. Em 1996, o número de rapazes na faixa de 15 a 24 anos foi superior em $14 \%$ ao número de moças, indicando um processo de masculinização rural (CAMARANO e ABRAMOVAY, 1999). Assim, pode-se afirmar que esse grupo estudado não está sofrendo processo de masculinização e que a permanência da mulher pode relacionar-se a multifuncionalidade do espaço rural e a pluriatividade da agricultura familiar.

A pirâmide etária exposta na Figura 1, classifica a população estudada de acordo com seu gênero e suas faixas de idade, sendo essas informações importantes para ações planejadas em relação aos seus membros.

\footnotetext{
${ }^{6}$ Expressão (moças e rapazes) utilizada pelos autores do artigo. 
Figura 1 - Pirâmide etária dos membros residentes das unidades familiares

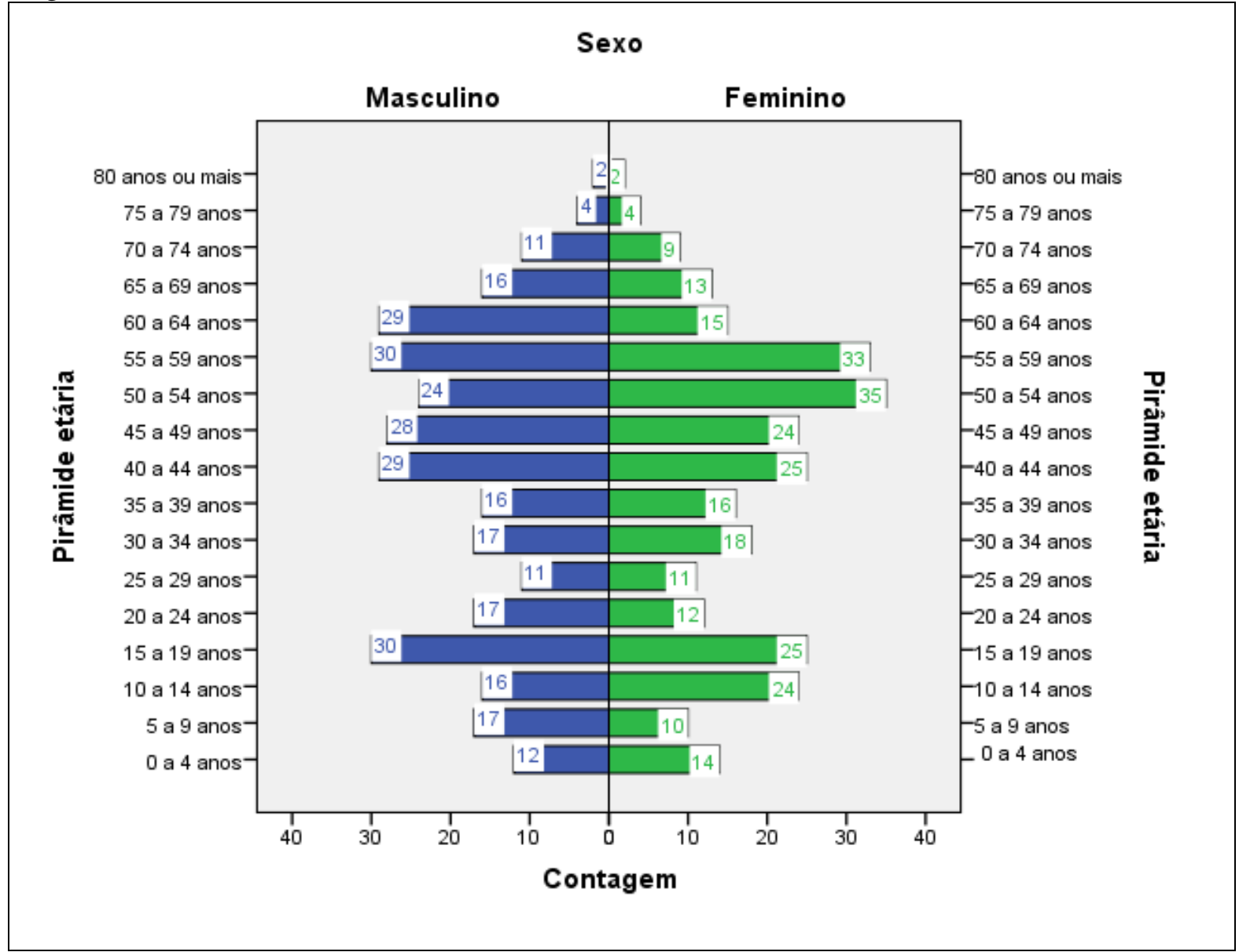

Fonte: Dados da pesquisa (2020).

Verificou-se que não é uma pirâmide jovem, pois as suas famílias não são numerosas, sofre um achatamento nas faixas etárias de 20 a 39 anos pela diminuição de membros residentes, voltando a maiores de concentração nas faixas de 40 a 59 anos.

\begin{abstract}
Segundo Sakamoto e Maia (2013) ocorreu uma redução da taxa de fecundidade das mulheres, e importantes mudanças na estrutura das famílias brasileiras nas últimas décadas. De um lado, houve uma forte redução da família nuclear (constituída por casais com filhos) e, de outro, uma expansão das famílias formadas por membros individuais e por casais sem filhos. Por exemplo, entre 1981 e 2011, a participação das famílias nucleares caiu de $74 \%$ para $58 \%$ do total de famílias e aumentou em 8 pontos percentuais (de 4\% para 12\%) a participação dos casais sem filhos nas áreas rurais (Sakamoto e Maia, 2013 apud MAIA e BUAINAIN, 2015, p.04)
\end{abstract}

No momento, não é uma pirâmide envelhecida, porém, nos próximos anos poderá ser considerada como tal, em virtude de a população estar caminhando para o topo da pirâmide, com faixas etárias acima de 60 anos e predominância de homens nessa faixa.

$\mathrm{Na}$ Tabela 3, estão tratados os dados educacionais dos membros residentes das unidades familiares levando em consideração duas variáveis: a primeira o grau de escolaridade, seguida por uma projeção de idade escolar da educação infantil até o ensino superior. 
Constatou-se baixa taxa de analfabetismo, pois dentre os membros considerados sem instrução a maioria tem idade de até 5 anos, indicando que somente $1,7 \%$ do grupo estudado com idade escolar não tem instrução e estão concentrados em faixas etárias superiores a 17 anos. Quanto ao ensino fundamental, parte significativa do grupo estudado tem ensino fundamental incompleto $(43,6 \%)$ e $9,7 \%$ dos casos tem ensino fundamental completo, demonstrando a faixa predominante dentro das características educacionais, mas apresentam idade escolar equivalente ao ensino superior; quanto ao ensino médio foram levantados dados significativos, onde $10,5 \%$ possuem ensino médio incompleto e $21,4 \%$ completo, porém também estão concentrados na projeção de idade escolar relacionada ao ensino superior.

Em se tratando de ensino superior, constatou-se baixa representatividade entre os membros, onde somente 3,5\% tem ensino superior incompleto e 4,8\% completo. Pode-se inferir que nas áreas rurais a oferta de empregos qualificados e de elevada remuneração é restrita, em muitas até mesmo inexistente, no caso de pessoas com ensino superior (MAIA e BUAINAIN, 2015).

Segundo Schneider et al. (2006), os níveis de escolaridade têm efeitos sobre a renda e a qualidade de vida dos agricultores, constatando que famílias pluriativas apresentam maior nível de escolaridade. Observou-se que a possibilidade de membros familiares exercerem atividades não agrícolas está relacionada com a formação acadêmica superior, porém cita Etxezarreta et al. (1995), que não se pode estabelecer relação de que o maior nível de instrução ocasione necessariamente melhores condições de vida ou melhores rendimentos. 
Tabela 3 - Características educacionais dos membros residentes das unidades familiares em relação a idade escolar

\begin{tabular}{|c|c|c|c|c|c|c|}
\hline \multirow[b]{2}{*}{ Escolaridade } & & \multicolumn{4}{|c|}{ Idade Escolar } & \multirow[b]{2}{*}{ Total } \\
\hline & & $\begin{array}{c}\text { Educação } \\
\text { infantil } \\
\text { (1 a } 5 \text { anos) }\end{array}$ & $\begin{array}{c}\text { Ensino } \\
\text { fundamental } \\
\text { ( } 6 \text { a } 14 \text { anos) }\end{array}$ & $\begin{array}{c}\text { Ensino } \\
\text { médio } \\
(15 \text { a } 17 \\
\text { anos })\end{array}$ & $\begin{array}{c}\text { Ensino } \\
\text { Superior } \\
\text { (Acima de } \\
17 \text { anos) }\end{array}$ & \\
\hline \multirow{3}{*}{ Sem instrução } & Contagem & 29 & 0 & 0 & 10 & 39 \\
\hline & $\%$ Escolaridade & $74,4 \%$ & $0,0 \%$ & $0,0 \%$ & $25,6 \%$ & $100,0 \%$ \\
\hline & $\%$ do Total & $4,8 \%$ & $0,0 \%$ & $0,0 \%$ & $1,7 \%$ & $6,5 \%$ \\
\hline \multirow{3}{*}{ Fundamental incompleto } & Contagem & 0 & 58 & 4 & 199 & 261 \\
\hline & $\%$ Escolaridade & $0,0 \%$ & $22,2 \%$ & $1,5 \%$ & $76,2 \%$ & $100,0 \%$ \\
\hline & $\%$ do Total & $0,0 \%$ & $9,7 \%$ & ,7\% & $33,2 \%$ & $43,6 \%$ \\
\hline \multirow{3}{*}{ Fundamental completo } & Contagem & 0 & 2 & 0 & 56 & 58 \\
\hline & $\%$ Escolaridade & $0,0 \%$ & $3,4 \%$ & $0,0 \%$ & $96,6 \%$ & $100,0 \%$ \\
\hline & $\%$ do Total & $0,0 \%$ &, $3 \%$ & $0,0 \%$ & $9,3 \%$ & $9,7 \%$ \\
\hline \multirow{3}{*}{ Médio incompleto } & Contagem & 0 & 4 & 32 & 27 & 63 \\
\hline & $\%$ Escolaridade & $0,0 \%$ & $6,3 \%$ & $50,8 \%$ & $42,9 \%$ & $100,0 \%$ \\
\hline & $\%$ do Total & $0,0 \%$ &, $7 \%$ & $5,3 \%$ & $4,5 \%$ & $10,5 \%$ \\
\hline \multirow{3}{*}{ Médio Completo } & Contagem & 0 & 0 & 0 & 128 & 128 \\
\hline & $\%$ Escolaridade & $0,0 \%$ & $0,0 \%$ & $0,0 \%$ & $100,0 \%$ & $100,0 \%$ \\
\hline & $\%$ do Total & $0,0 \%$ & $0,0 \%$ & $0,0 \%$ & $21,4 \%$ & $21,4 \%$ \\
\hline \multirow{3}{*}{ Superior incompleto } & Contagem & 0 & 0 & 0 & 21 & 21 \\
\hline & $\%$ Escolaridade & $0,0 \%$ & $0,0 \%$ & $0,0 \%$ & $100,0 \%$ & $100,0 \%$ \\
\hline & $\%$ do Total & $0,0 \%$ & $0,0 \%$ & $0,0 \%$ & $3,5 \%$ & $3,5 \%$ \\
\hline \multirow{3}{*}{ Superior completo } & Contagem & 0 & 0 & 0 & 29 & 29 \\
\hline & $\%$ Escolaridade & $0,0 \%$ & $0,0 \%$ & $0,0 \%$ & $100,0 \%$ & $100,0 \%$ \\
\hline & $\%$ do Total & $0,0 \%$ & $0,0 \%$ & $0,0 \%$ & $4,8 \%$ & $4,8 \%$ \\
\hline \multirow{3}{*}{ Total } & Contagem & 29 & 64 & 36 & 470 & 599 \\
\hline & \% Escolaridade & $4,8 \%$ & $10,7 \%$ & $6,0 \%$ & $78,5 \%$ & $100,0 \%$ \\
\hline & $\%$ do Total & $4,8 \%$ & $10,7 \%$ & $6,0 \%$ & $78,5 \%$ & $100,0 \%$ \\
\hline
\end{tabular}

Fonte: Dados da pesquisa (2020).

Com as informações da Tabela 4, onde o grau de instrução está em tabulação cruzada com a faixa etária, em síntese, pode-se verificar que os reflexos dos níveis de escolaridade são observados a partir da faixa etária de 30 anos ou mais, onde grande parte possui ensino fundamental incompleto seguido pelo ensino médio completo, possuem baixa representatividade de membros com idade escolar sem instrução e com ensino superior relacionado predominantemente a faixa etária entre 20 e 49 anos. Pode-se inferir que as gerações mais antigas sofreram um processo de atraso educacional, o que pode ser revertido para as novas gerações, já que se encontram em grande maioria com faixas etárias e idade escolar compatíveis.

Segundo Abramovay et al. (2001), em uma pesquisa com agricultores familiares do oeste de Santa Catarina, foi constatado um atraso educacional entre jovens, potenciais sucessores das unidades estudadas, o que gerou dificuldade no desempenho da atividade agrícola, em termos de organização e de introdução de novas atividades, comprometendo em alguns casos o próprio exercício da cidadania, não permitindo acesso a direitos legalmente constituídos. 
Tabela 4 - Características educacionais dos membros residentes das unidades familiares em relação as faixas etárias

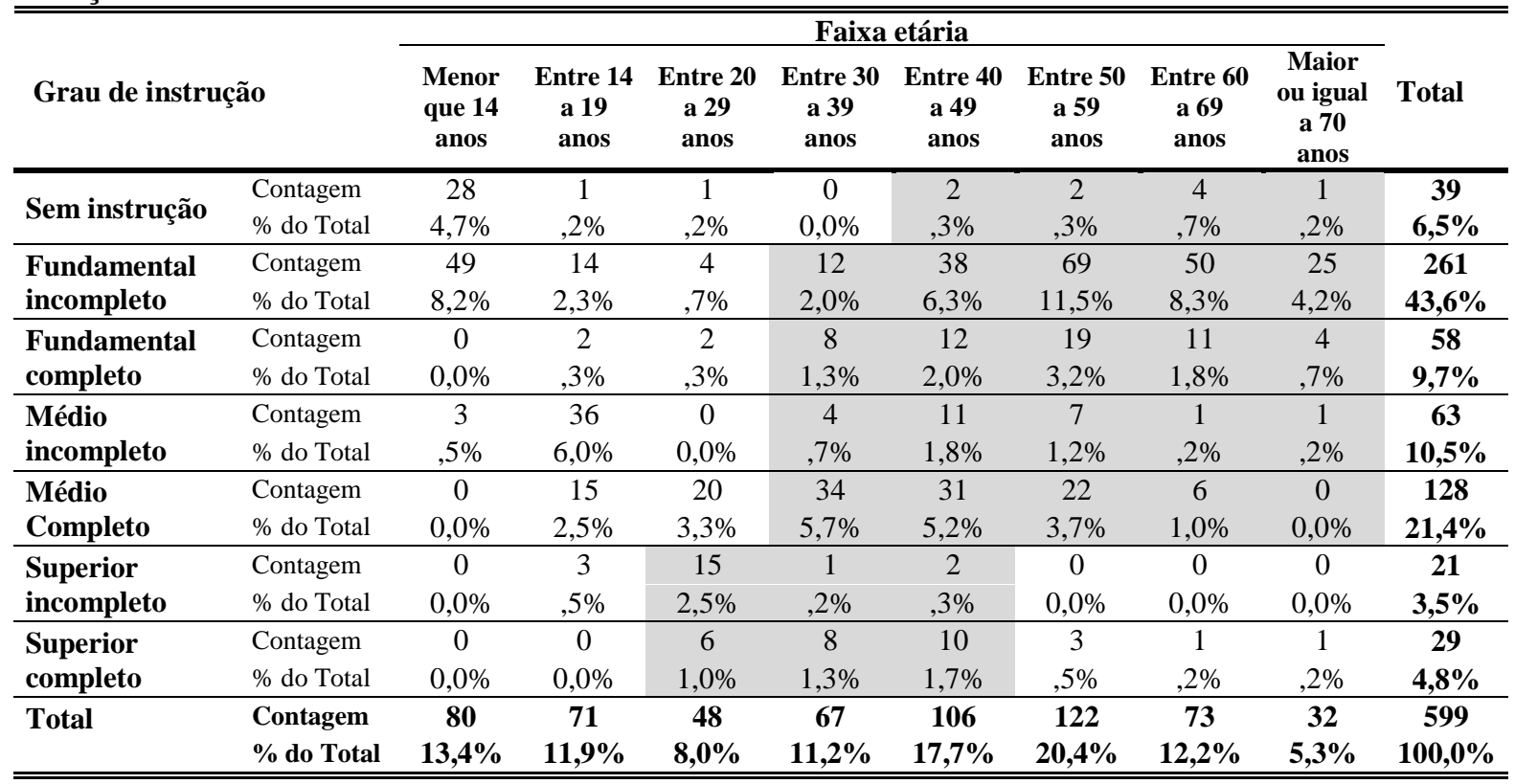

Fonte: Dados da pesquisa (2020).

$\mathrm{Na}$ Tabela 5, constam as informações relacionadas ao estado civil dos membros residentes nas unidades familiares, onde a grande maioria apresenta-se como casado, distribuídos nas faixas acima de 20 anos. Os solteiros estão distribuídos nas faixas etárias até 39 anos, porém, concentrados nas faixas de até 29 anos e há pouca representatividade de viúvos e divorciados. Pelos números encontrados, pode-se inferir que a amostra estudada é predominantemente casada em faixas etárias ascendentes, demonstrando que a gestão da propriedade está relacionada ao casal, dispõe de juventude predominantemente solteira até os 19 anos e valor expressivo de solteiros entre as faixas de 20 a 39 anos, estes que poderão aprender e se adaptar ao meio de vida rural ou mesmo constituir relação familiar fora deste eixo.

Tabela 5 - Características dos membros residentes das unidades familiares em relação ao estado civil e faixa etária

\begin{tabular}{|c|c|c|c|c|c|c|c|c|c|c|}
\hline \multirow[b]{2}{*}{ Estado civil } & & \multicolumn{8}{|c|}{ Faixa etária } & \multirow[b]{2}{*}{ Total } \\
\hline & & $\begin{array}{c}\text { Menor } \\
\text { que 14 } \\
\text { anos } \\
\end{array}$ & $\begin{array}{c}\text { Entre } 14 \\
\text { a } 19 \\
\text { anos } \\
\end{array}$ & $\begin{array}{c}\text { Entre 20 } \\
\text { a 29 } \\
\text { anos } \\
\end{array}$ & $\begin{array}{c}\text { Entre 30 } \\
\text { a 39 } \\
\text { anos } \\
\end{array}$ & $\begin{array}{c}\text { Entre 40 } \\
\text { a 49 } \\
\text { anos } \\
\end{array}$ & $\begin{array}{c}\text { Entre 50 } \\
\text { a 59 } \\
\text { anos } \\
\end{array}$ & $\begin{array}{c}\text { Entre 60 } \\
\text { a } 69 \\
\text { anos } \\
\end{array}$ & $\begin{array}{c}\text { Maior ou } \\
\text { igual a 70 } \\
\text { anos } \\
\end{array}$ & \\
\hline Casado & $\begin{array}{l}\text { Contagem } \\
\% \text { do Total }\end{array}$ & $\begin{array}{c}0 \\
0,0 \%\end{array}$ & $\begin{array}{c}1 \\
, 2 \%\end{array}$ & $\begin{array}{c}12 \\
2,0 \%\end{array}$ & $\begin{array}{c}53 \\
8,8 \%\end{array}$ & $\begin{array}{c}103 \\
17,2 \%\end{array}$ & $\begin{array}{c}115 \\
19,2 \%\end{array}$ & $\begin{array}{c}68 \\
11,4 \%\end{array}$ & $\begin{array}{c}24 \\
4,0 \%\end{array}$ & $\begin{array}{c}376 \\
62,8 \%\end{array}$ \\
\hline Solteiro & $\begin{array}{l}\text { Contagem } \\
\% \text { do Total } \\
\end{array}$ & $\begin{array}{c}80 \\
13,4 \% \\
\end{array}$ & $\begin{array}{c}70 \\
11,7 \% \\
\end{array}$ & $\begin{array}{r}36 \\
6,0 \% \\
\end{array}$ & $\begin{array}{c}14 \\
2,3 \% \\
\end{array}$ & $\begin{array}{c}2 \\
, 3 \% \\
\end{array}$ & $\begin{array}{c}1 \\
, 2 \% \\
\end{array}$ & $\begin{array}{c}1 \\
, 2 \% \\
\end{array}$ & $\begin{array}{c}0 \\
0,0 \% \\
\end{array}$ & $\begin{array}{c}204 \\
34,1 \% \\
\end{array}$ \\
\hline Viúvo & $\begin{array}{l}\text { Contagem } \\
\% \text { do Total }\end{array}$ & $\begin{array}{c}0 \\
0,0 \%\end{array}$ & $\begin{array}{c}0 \\
0,0 \%\end{array}$ & $\begin{array}{c}0 \\
0,0 \%\end{array}$ & $\begin{array}{c}0 \\
0,0 \%\end{array}$ & $\begin{array}{c}1 \\
, 2 \%\end{array}$ & $\begin{array}{c}5 \\
, 8 \%\end{array}$ & $\begin{array}{c}4 \\
, 7 \%\end{array}$ & $\begin{array}{c}8 \\
1,3 \%\end{array}$ & $\begin{array}{c}18 \\
3,0 \%\end{array}$ \\
\hline Divorciado & $\begin{array}{l}\text { Contagem } \\
\% \text { do Total }\end{array}$ & $\begin{array}{c}0 \\
0,0 \% \\
\end{array}$ & $\begin{array}{c}0 \\
0,0 \% \\
\end{array}$ & $\begin{array}{c}0 \\
0,0 \% \\
\end{array}$ & $\begin{array}{c}0 \\
0,0 \% \\
\end{array}$ & $\begin{array}{c}0 \\
0,0 \% \\
\end{array}$ & $\begin{array}{c}1 \\
, 2 \% \\
\end{array}$ & $\begin{array}{c}0 \\
0,0 \% \\
\end{array}$ & $\begin{array}{c}0 \\
0,0 \% \\
\end{array}$ & $\begin{array}{c}1 \\
, 2 \% \\
\end{array}$ \\
\hline Total & $\begin{array}{l}\text { Contagem } \\
\% \text { do Total }\end{array}$ & $\begin{array}{c}80 \\
13,4 \%\end{array}$ & $\begin{array}{c}71 \\
11,9 \% \\
\end{array}$ & $\begin{array}{c}48 \\
8,0 \%\end{array}$ & $\begin{array}{c}67 \\
11,2 \%\end{array}$ & $\begin{array}{c}106 \\
17,7 \% \\
\end{array}$ & $\begin{array}{c}122 \\
20,4 \% \\
\end{array}$ & $\begin{array}{c}73 \\
12,2 \%\end{array}$ & $\begin{array}{c}32 \\
5,3 \%\end{array}$ & $\begin{array}{c}599 \\
100,0 \%\end{array}$ \\
\hline
\end{tabular}

Fonte: Dados da pesquisa (2020). 
Segundo Stropasolas (2004), pela análise das representações e inciativas da juventude rural na região Oeste de Santa Catarina, verificou-se o surgimento futuro de conflitos nas escolhas dos modelos de família e casamento, repercutindo nos projetos de vida formulados pelas moças e rapazes rurais, provocando uma tendência de gênero no movimento migratório dos jovens, pois atualmente na agricultura familiar o sonho da afirmação no matrimônio é antecedido por várias interrogações, principalmente pelas moças que costumam receber o não em seu cotidiano, em compensação do lugar que ocupam ou querem conquistar na família, comunidade e sociedade.

Vários são os aspectos de importância na agricultura familiar, como as tradições, produção e trabalho, sendo o trabalho no estabelecimento altamente relacionado a reprodução social dessas famílias. A população que vive nas áreas rurais possui diversificação, tanto no espaço ocupado, quanto nas tradições que mantém e na identidade que formou, é a função sociocultural da agricultura familiar, que significa o resgate de um modo de vida que associa conceitos de cultura, tradição e identidade (ALTAFIN, 2007, WANDERLEY, 2009).

Na Tabela 6, identificou-se que os jovens menores de 14 anos não dedicam mão de obra a propriedade, parcela essa em idade escolar e relacionada as questões legais sobre o trabalho infantil. Entre os jovens de 14 a 19 anos, aponta-se valor considerável de não dedicação de mão de obra no estabelecimento, quando há a dedicação de mão de obra a propriedade estão distribuídas de maneira parcial semanal.

Constatou-se que nas faixas entre 20 e 59 anos, embora haja um percentual de membros que não dediquem mão de obra ao estabelecimento, é a faixa etária em que é maior a concentração de trabalho relacionamento ao estabelecimento, bem como onde se apresentam as maiores incidências de dedicação desses membros nos 7 dias da semana.

O que chama a atenção é a dedicação de mão de obra, na maioria de forma integral, dos membros com idade superior a 60 anos, demonstrando a necessidade de mão de obra e demanda de trabalho dentro destas unidades estudadas. De maneira geral, pode-se concluir que os jovens dedicam pouco ou nenhuma mão de obra a propriedade, que a concentração de mão de obra empregada está relacionada com a faixa etária entre 20 e 59 anos, concentradas acima de 5 dias na semana e que mesmos os membros que estão em faixa etária considerada alta, acima de 60 anos não deixaram de empregar mão de obra constante no estabelecimento.

Dentro desta constatação, abre-se uma lacuna que depende de uma análise mais aprofundada destes estabelecimentos, pois de acordo com Buainain (2006), deve-se considerar a relação entre os sistemas produtivos e a disponibilidade de mão de obra, pois sistemas ou tecnologia podem intensificar ou poupar o uso de mão de obra, podendo também aumentar a sazonalidade da demanda de trabalho. Dessa maneira, a disponibilidade do trabalho familiar ou contratação durante o período de pico é um fator determinante de mudança, pois a introdução de tecnologias de base química e mecânica ocasionou uma considerável redução do emprego da mão de obra. 
Tabela 6 - Dedicação de mão de obra dos membros residentes das unidades familiares em relação a faixa etária

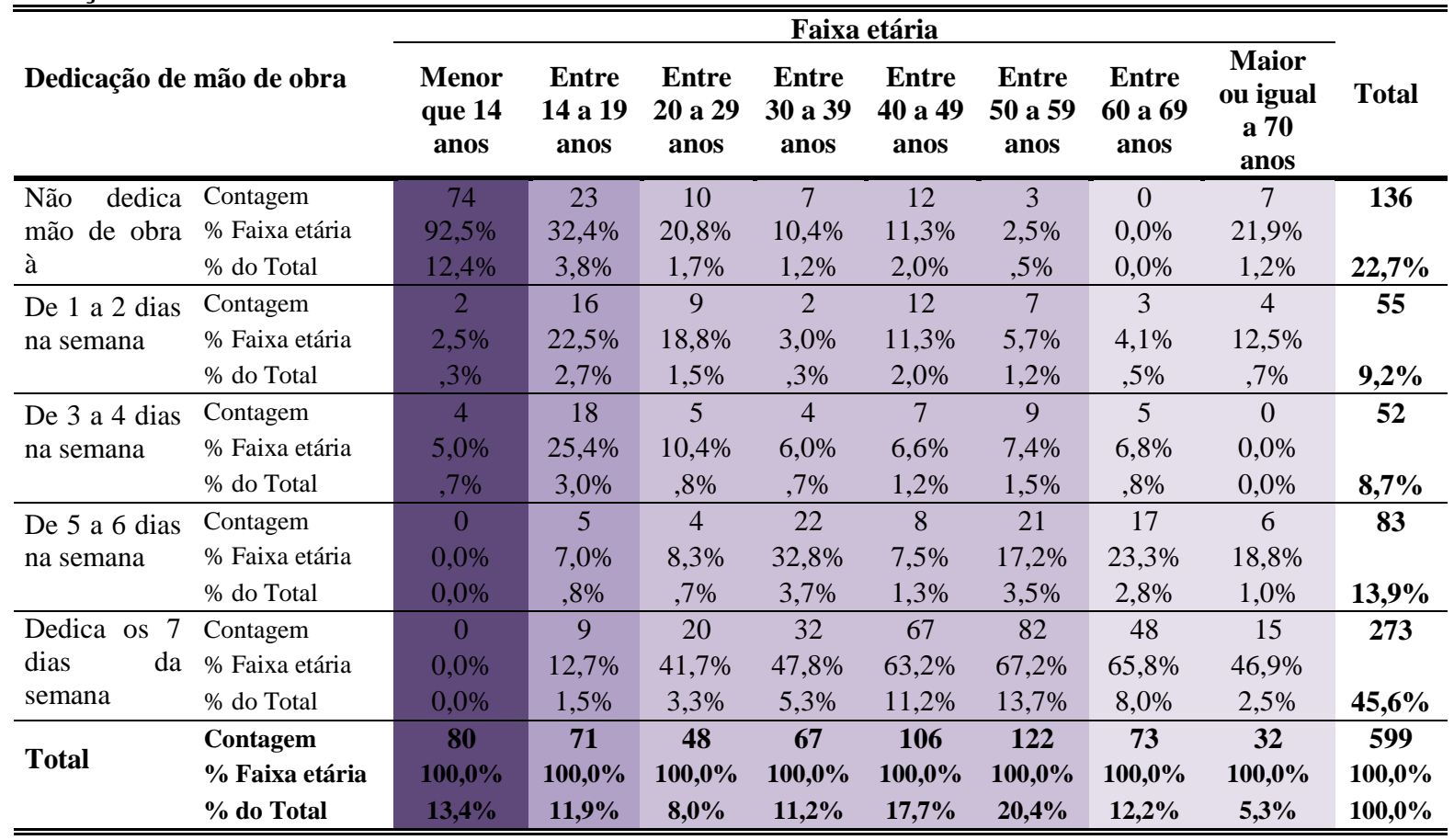

Fonte: Dados da pesquisa (2020).

As informações da Tabela 7 evidenciam a distribuição da mão de obra dos membros residentes aos seus respectivos gêneros, comparando a dedicação dos homens e mulheres dentro destas unidades familiares.

Identificou-se a grande participação da mulher nestes estabelecimentos, elas participam de forma ativa em relação a mão de obra em conjunto com os homens, provavelmente acumulando atividades domésticas e assistência aos filhos menores. As mulheres possuem um papel importante na agricultura, diante de sua diversidade e múltiplas funções exercidas, desde os afazeres da casa, aos cuidados da família e nas tarefas das atividades de produção agropecuária (PASSINI, 2020).

Essas informações podem definir uma mudança de conceito dentro destes estabelecimentos estudados, onde a mulher participa dentro da esfera produtiva, pois de acordo com Araújo e Scalon (2005), na agricultura a relação de gênero é sinalizada por uma classe entre os indivíduos, sendo as mulheres em esferas menos valorizadas, como a reprodução e atividades domésticas e os homens na esfera de produção e atividades na vida pública, estas mais valorizadas na vida social. Segundo Arzabe e Daller (2020), o trabalho da mulher era invisível, e a parte da gestão e as questões financeiras eram responsabilidade dos maridos, pais ou irmãos. Esse cenário pode estar mudando, pois, um número cada vez maior de mulheres está se ocupando de atividades financeiras e gestão de negócios, elas já administram em torno de 30 milhões de hectares (PASSINI, 2020). 
Tabela 7 - Dedicação de mão de obra dos membros residentes das unidades familiares em relação ao gênero

\begin{tabular}{|c|c|c|c|c|}
\hline \multirow[t]{2}{*}{ Dedicação de mão de obra } & & \multicolumn{2}{|c|}{ Sexo } & \multirow[t]{2}{*}{ Total } \\
\hline & & Masculino & Feminino & \\
\hline \multirow{3}{*}{ Não dedica mão de obra à propriedade } & Contagem & 64 & 72 & 136 \\
\hline & $\%$ dentro de Sexo & $20,7 \%$ & $24,8 \%$ & \\
\hline & $\%$ do Total & $10,7 \%$ & $12,0 \%$ & $22,7 \%$ \\
\hline \multirow{3}{*}{ De 1 a 2 dias na semana } & Contagem & 29 & 26 & 55 \\
\hline & $\%$ dentro de Sexo & $9,4 \%$ & $9,0 \%$ & \\
\hline & $\%$ do Total & $4,8 \%$ & $4,3 \%$ & $9,2 \%$ \\
\hline \multirow{3}{*}{ De 3 a 4 dias na semana } & Contagem & 26 & 26 & 52 \\
\hline & $\%$ dentro de Sexo & $8,4 \%$ & $9,0 \%$ & \\
\hline & $\%$ do Total & $4,3 \%$ & $4,3 \%$ & $8,7 \%$ \\
\hline \multirow{3}{*}{ De 5 a 6 dias na semana } & Contagem & 40 & 43 & 83 \\
\hline & $\%$ dentro de Sexo & $12,9 \%$ & $14,8 \%$ & \\
\hline & $\%$ do Total & $6,7 \%$ & $7,2 \%$ & $13,9 \%$ \\
\hline \multirow{3}{*}{ Dedica os 7 dias da semana } & Contagem & 150 & 123 & 273 \\
\hline & $\%$ dentro de Sexo & $48,5 \%$ & $42,4 \%$ & \\
\hline & $\%$ do Total & $25,0 \%$ & $20,5 \%$ & $45,6 \%$ \\
\hline \multirow{3}{*}{ Total } & Contagem & 309 & 290 & 599 \\
\hline & \% dentro de Sexo & $100,0 \%$ & $100,0 \%$ & $100,0 \%$ \\
\hline & $\%$ do Total & $51,6 \%$ & $48,4 \%$ & $100,0 \%$ \\
\hline
\end{tabular}

Fonte: Dados da pesquisa (2020).

Colaborando com as informações anteriores, a Tabela 8 identifica que dentre os membros em relação a mão de obra, tem-se médias uniformes em relação a idade, sendo que os homens com dedicação de mão de obra têm em média 46,04 anos e as mulheres 44,04 anos e quanto aos dias dedicados ao estabelecimento as médias também foi homogêneas, os homens empregam 5,55 dias e as mulheres 5,38 dias.

Tabela 8 - Dedicação média de mão de obra dos membros residentes das unidades familiares

\begin{tabular}{llcccc}
\hline \hline Variáveis & Sexo & N & Média & Desvio padrão & $\begin{array}{c}\text { Erro padrão da } \\
\text { média }\end{array}$ \\
\hline Idade & Masculino & 245 & 46,04 & 17,002 & 1,086 \\
& Feminino & 218 & 44,86 & 16,625 & 1,126 \\
\hline Dias dedicados & a Masculino & 245 & 5,55 & 1,869 &, 119 \\
propriedade ano & Feminino & 218 & 5,38 & 1,917 &, 130 \\
\hline \hline
\end{tabular}

Fonte: Dados da pesquisa (2020).

Na Tabela 9, aplicou-se o teste de igualdade de variâncias de Levene calculados com relação as variáveis anteriores, que apresentou valor de sig maior que 0,05 nos dois casos analisados, na variável idade 0,653 e na variável dias dedicados a propriedade na semana 0,914. Deste modo, conclui-se que existe homogeneidade de variâncias e não existem evidências de diferenças estatísticas significativas entre as médias, tanto em relação à idade dos agricultores, quanto aos dias dedicados a propriedade em relação aos homens e mulheres. 
Tabela 9 - Dedicação de mão de obra dos membros residentes das unidades familiares

\begin{tabular}{|c|c|c|c|c|c|c|c|c|c|c|}
\hline & & \multicolumn{2}{|c|}{$\begin{array}{l}\text { Teste de } \\
\text { Levene }\end{array}$} & \multicolumn{7}{|c|}{ Teste-t para Igualdade de Médias } \\
\hline & & \multirow[t]{2}{*}{$\mathbf{F}$} & \multirow[t]{2}{*}{ Sig. } & \multirow[t]{2}{*}{$\mathbf{t}$} & \multirow[t]{2}{*}{ Df } & \multirow[t]{2}{*}{$\begin{array}{c}\text { Sig. (2 } \\
\text { extremidades) }\end{array}$} & \multirow[t]{2}{*}{$\begin{array}{c}\neq \\
\text { média }\end{array}$} & \multirow[t]{2}{*}{$\begin{array}{c}\text { Erro } \\
\text { padrão de } \\
\text { diferença }\end{array}$} & \multicolumn{2}{|c|}{$\begin{array}{c}95 \% \text { Intervalo de } \\
\text { confiança da } \\
\text { diferença }\end{array}$} \\
\hline & & & & & & & & & Inferior & Superior \\
\hline Idade & $\begin{array}{l}\text { Variâncias } \\
\text { iguais } \\
\text { assumidas }\end{array}$ & ,203 & ,653 &, 750 & 461 & ,454 & 1,174 & 1,567 & $-1,904$ & 4,253 \\
\hline $\begin{array}{l}\text { Dias } \\
\text { dedicados a } \\
\text { propriedade } \\
\text { na semana }\end{array}$ & $\begin{array}{l}\text { Variâncias } \\
\text { iguais } \\
\text { assumidas }\end{array}$ &, 012 & ,914 & ,967 & 461 &, 334 &, 170 &, 176 &,- 176 &, 516 \\
\hline
\end{tabular}

Fonte: Dados da pesquisa (2020).

Pela identificação da existência de casos de aplicação de mão de obra em tempo parcial nos estabelecimentos estudados, na Tabela 10, levantou-se informações sobre fontes de rendas extra agrícolas ou não agrícolas destas famílias, sem informações em relação a valores auferidos.

Tabela 10 - Fonte de renda extra agrícola dos membros residentes das unidades familiares em relação ao gênero

\begin{tabular}{|c|c|c|c|c|c|c|}
\hline \multirow{2}{*}{ Fonte de renda extra agrícola } & \multicolumn{4}{|c|}{ \% dentro do gênero } & \multicolumn{2}{|c|}{ \% dentro do Total } \\
\hline & Masculino & $\%$ & Feminino & $\%$ & Quantidade & $\%$ \\
\hline Não possuem renda extra agrícola & 199 & $50,4 \%$ & 196 & $49,6 \%$ & 395 & $65,9 \%$ \\
\hline Aposentadoria & 61 & $50,0 \%$ & 61 & $50,0 \%$ & 122 & $20,4 \%$ \\
\hline Assalariado (não informou fonte) & 22 & $71,0 \%$ & 9 & $29,0 \%$ & 31 & $5,2 \%$ \\
\hline Serviços Gerais (diárias) & 12 & $75,0 \%$ & 4 & $25,0 \%$ & 16 & $2,7 \%$ \\
\hline Pedreiro & 5 & $83,3 \%$ & 1 & $16,7 \%$ & 6 & $1,0 \%$ \\
\hline Funcionário público & 1 & $20,0 \%$ & 4 & $80,0 \%$ & 5 & $0,8 \%$ \\
\hline Professor & 0 & $0,0 \%$ & 4 & $100,0 \%$ & 4 & $0,7 \%$ \\
\hline Feirante & 1 & $33,3 \%$ & 2 & $66,7 \%$ & 3 & $0,5 \%$ \\
\hline Vigia & 3 & $100,0 \%$ & 0 & $0,0 \%$ & 3 & $0,5 \%$ \\
\hline Doméstica & 0 & $0,0 \%$ & 2 & $100,0 \%$ & 2 & $0,3 \%$ \\
\hline Cozinheira & 0 & $0,0 \%$ & 2 & $100,0 \%$ & 2 & $0,3 \%$ \\
\hline Costureira & 0 & $0,0 \%$ & 2 & $100,0 \%$ & 2 & $0,3 \%$ \\
\hline Mecânico & 1 & $100,0 \%$ & 0 & $0,0 \%$ & 1 & $0,2 \%$ \\
\hline Técnico Agrícola & 1 & $100,0 \%$ & 0 & $0,0 \%$ & 1 & $0,2 \%$ \\
\hline Cabelereira & 0 & $0,0 \%$ & 1 & $100,0 \%$ & 1 & $0,2 \%$ \\
\hline Pensão & 0 & $0,0 \%$ & 1 & $100,0 \%$ & 1 & $0,2 \%$ \\
\hline Benefício Inss "Acidente ou doença" & 1 & $100,0 \%$ & 0 & $0,0 \%$ & 1 & $0,2 \%$ \\
\hline Frete de animais & 1 & $100,0 \%$ & 0 & $0,0 \%$ & 1 & $0,2 \%$ \\
\hline Advogado & 1 & $100,0 \%$ & 0 & $0,0 \%$ & 1 & $0,2 \%$ \\
\hline Pintora & 0 & $0,0 \%$ & 1 & $100,0 \%$ & 1 & $0,2 \%$ \\
\hline Total com renda extra agrícola & 110 & $53,9 \%$ & 94 & $46,1 \%$ & 204 & $34,1 \%$ \\
\hline Total geral & 309 & $51,6 \%$ & 290 & $48,4 \%$ & 599 & $10 \overline{100,0 \%}$ \\
\hline
\end{tabular}

Fonte: Dados da pesquisa (2020).

Constatou-se que $65,9 \%$ dos membros residentes não possuem renda extra agrícola, entre os membros com este tipo de renda, $(20,4 \%)$ a fonte advinda de aposentadorias é a principal, seguida pelas diversas outras funções desempenhadas pelos agricultores fora de sua propriedade que lhes rendem remuneração. Quanto à questão de 
gênero, em relação a aposentadoria, apresenta-se uniforme entre homens e mulheres, devido ao benefício estar ligado as respectivas faixas etárias.

Em relação às demais atividades verificou-se uma distribuição de profissões que tem relação com o gênero destes membros, porém, de maneira geral os homens apresentam maior índice de renda extra agrícola que as mulheres.

Para Niederle (2017), quando a agricultura não é suficiente, inclui-se fontes pelas vias de industrialização ou servicialização, identificados por analistas desde 1990, como alternativa de reprodução social da agricultura familiar as atividades não agrícolas e a pluriatividade, opção não somente para famílias empobrecidas, mas também para indivíduos que ficaram desocupados pela mecanização da agricultura.

Atualmente, há quem aponte que o mercado de trabalho urbano absorva parcela da população agrícola que seria não socialmente produtiva ou competitiva na agricultura, seja de estabelecimentos com acesso insuficiente aos meios de produção ou que dispensam mão de obra devido a níveis de automação (NIEDERLE, 2017).

Campanhola e Graziano da Silva (2000, p. 1), apontam que há três grandes segmentos na composição econômica no novo mundo rural: "a) Uma agricultura moderna, baseada em "commodities" e intimamente ligada às agroindústrias. b) Um conjunto de atividades não agrícolas ligadas à moradia, ao lazer e a várias atividades industriais e à prestação de serviços. c) Um conjunto de "novas" atividades agropecuárias impulsionadas por nichos especiais de mercado".

As atividades não agrícolas, que compõem a pluriatividade das famílias que residem no rural brasileiro, são muito importantes para a permanência de muitas delas no campo (ELESBÃO, 2007). Na pesquisa, identificou-se atividades não agrícolas, mas não há menção sobre novas atividades agropecuárias. É uma lacuna, que pode abrir outras perspectivas de geração de renda.

Quanto aos valores recebidos, conforme a Tabela 11, das unidades, 26,7\% concentram-se na faixa entre 1 e 2 salários-mínimos que contribuem para a ampliação da renda familiar, como representado nas fontes de renda na tabela anterior, sendo elas múltiplas, porém, com destaque para a aposentadoria, inferindo que esta faixa de renda possa ter uma parcela relacionada a ela.

Tabela 11 - Faixa mensal de renda extra agrícola dos membros residentes das unidades familiares

\begin{tabular}{lcc}
\hline \hline Faixa de renda mensal extra agrícola & Frequência & \% \\
\hline Não possui renda extra agrícola & 396 & $66,1 \%$ \\
Menor que 1 salário mínimo & 18 & $3,0 \%$ \\
Entre 1 e 2 salários mínimos & 160 & $26,7 \%$ \\
Entre 3 e 4 salários mínimos & 24 & $4,0 \%$ \\
Acima de 4 salários mínimos & 1 & $0,2 \%$ \\
\hline Total & $\mathbf{5 9 9}$ & $\mathbf{1 0 0 , 0 \%}$ \\
\hline \hline
\end{tabular}

Fonte: Dados da pesquisa (2020).

Para Kageyama (2001) no Brasil, possivelmente é de maior importância o conceito de pluriatividade, o conceito de rendas múltiplas, pois existe uma quantidade de rendas não oriundas do trabalho como o caso das aposentadorias rurais, essenciais para a sobrevivência de familiar agrícolas mais empobrecidas e residentes em regiões menos favorecidas.

Nesse sentido, em resposta à pergunta do estudo, os dados apontaram que as características sociais dos membros de unidades familiares na Costa Oeste Paranaense e sua relação com a nova ruralidade, destaca-se em relação a composição familiar, a ocorrência 
de pequenas famílias, em média com 3 membros residentes e parcela considerável de unidades onde somente residem o casal, com faixa etária dos membros concentrada entre 30 a 59 anos, com paridade de gênero nestas unidades.

Verificou-se que os membros destas unidades não apresentam características de população jovem, apresentando características de processo de envelhecimento nos próximos anos, devido ao avanço para as faixas etárias acima de 60 anos.

Existe baixa taxa de analfabetismo, porém, existe grande concentração de membros com ensino fundamental incompleto, principalmente nas faixas etárias mais elevadas, comprovando que uma disparidade entre a idade real dos membros relacionada com a idade escolar, indicando que a formação acadêmica está relacionada aos mais jovens e que as gerações mais antigas sofreram processo de atraso educacional.

Os membros das unidades estudadas são predominantemente casados nas faixas etárias ascendentes, característica da composição familiar representada pelo casal. Os jovens até 19 anos são solteiros, porém existe considerável número de solteiros entre as faixas de 20 a 39 anos, com possibilidade de constituição de vínculo familiar fora do eixo rural.

Não existe dedicação considerável de mão de obra dos jovens até 19 anos, quando apontada, é de maneira parcial semanal, podendo estar relacionada a idade escolar destes membros e a questões legais sobre trabalho infantil. Identificou-se que os jovens dedicam pouca ou nenhuma mão de obra a propriedade, que a concentração de mão de obra empregada está relacionada com a faixa etária entre 20 e 59 anos, concentradas acima de 5 dias na semana e que mesmos os membros que estão em faixa etária considerada alta, acima de 60 anos não deixaram de empregar mão de obra constante no estabelecimento.

Identificou-se, existir homogeneidade de variâncias entre as médias, tanto quanto a idade dos agricultores e os dias dedicados a propriedade em relação aos homens e mulheres.

As unidades apresentaram indícios de pluriatividade, porém, é uma parcela pequena de membros residentes que possui renda extra agrícola. A principal renda extra agrícola é de aposentadoria, seguida pelas diversas outras funções desempenhadas pelos agricultores fora de sua propriedade que lhes rendem remuneração; a aposentadoria apresenta-se uniforme entre homens e mulheres devido ao benefício estar ligado as respectivas faixas etárias. Quanto as demais atividades, de maneira geral, os homens apresentam maior índice de renda extra agrícola que as mulheres, concentrada em uma faixa entre 1 e 2 saláriosmínimos. Essa pluriatividade, presente no novo rural brasileiro, é segundo Schneider (2009 p. 4) "a interação entre atividades agrícolas, para-agrícolas e não agrícolas, que tende a ser mais intensa à medida que mais complexas e diversificadas forem as relações entre os agricultores e o ambiente social e econômico em que estiverem inseridos" e que pode ser um recurso do qual a família faz uso para garantir a reprodução social e econômica, assim como pode representar uma estratégia individual (BOTELHO, 2005).

\section{CONSIDERAÇÕES FINAIS}

O estudo atingiu seu objetivo, de identificar as características de unidades familiares localizadas na região da Costa Oeste do Paraná, em relação aos membros residentes e suas relações com o novo rural brasileiro, contribuindo para a área do desenvolvimento rural ao 
demonstrar os aspectos desse novo rural e a sua importância para a agricultura familiar para seu desenvolvimento e manutenção.

As relações encontradas com a nova ruralidade dizem respeito a composição familiar, as características de processo de envelhecimento entre seus membros, oportunidade educacional aos mais jovens, porém, com processo de atraso para as gerações mais antigas. Não existe dedicação considerável de mão de obra dos jovens a propriedade, estas mais evidentes em relação aos mais velhos, existindo homogeneidade de variâncias entre as médias, tanto quanto a idade dos agricultores e os dias dedicados a propriedade em relação aos homens e mulheres. Há indícios de pluriatividade, porém a principal renda extra agrícola está relacionada a aposentadoria.

"O mundo rural é maior do que o agrícola" (GRAZIANO et al., 1996). Nesse sentido identificou-se uma lacuna quanto as atividades desenvolvidas pelos agricultores familiares da pesquisa. Eles possuem rendas não agrícolas, para aumentar a renda mensal, mas não desenvolvem outras atividades agrícolas, que poderiam contribuir para o aumento da renda.

Nesse caso, deveria ser feito um levantamento das potencialidades locais (atividades agrícolas e não agrícolas) para identificar as oportunidades de melhoria de renda para esses agricultores. O poder público também pode contribuir, nesse sentido, buscando implementar políticas públicas de fomento e investimento para o desenvolvimento das potencialidades locais.

Esta lacuna abre espaços para estudos futuros, para acompanhar frente ao contexto atual dos agricultores, tanto em relação a cidade e o campo e suas consequências no desenvolvimento desse novo rural.

\section{REFERÊNCIAS}

ÁGUAS PARANÁ - Instituto das Águas do Paraná. Plano de Bacia Hidrográfica do Paraná 3 - Características Gerais: Produto 1. 2014. Disponível em <http://www.aguasparana.pr.gov.br/arquivos/File/Parana_3/plano_de_bacia/Produto_01_C aracteristicas_Gerais_da_Bacia_BP3_2014_v07_Final.pdf >. Acessado em 16 dez. 2019. ABRAMOVAY, R., SILVESTRO, M. L., MELLO, M. D., DORIGON, C., BALDISSERA, I. T. Agricultura familiar e sucessão profissional: novos desafios. In: Anais do Congresso Brasileiro de Economia e Sociologia Rural. Vol. 39, 2001. ABRAMOVAY, Ricardo. Paradigmas do capitalismo agrário em questão. $3^{\circ}$ Edição. São Paulo: Edusp, 2012.

ALENTEJANO, Paulo Roberto R. O que há de novo no rural brasileiro?. Terra Livre, n. 15, p. 87-112, 2015.

ARAÚJO, C.; SCALON, C. (Org.). Gênero, família e trabalho no Brasil. Rio de Janeiro: FGV, 2005.

ALTAFIN, I. Reflexões sobre o conceito de agricultura familiar. 2007. Disponível em: https://www.feis.unesp.br/Home/departamentos/fitotecniatecnologiadealimentosesocioecon omia716/antoniolazarosantana/conceito-de-agricultura-familiar.pdf. Acesso em 16 jul 2021. BIOLABORE - Cooperativa de Trabalho e Assistência Técnica do Paraná. Projeto de Agricultura Orgânica na BP3, 2018.

BOTELHO FILHO, F.B. As portas de saída da pobreza e as estratégias da agricultura familiar para os negócios rurais. In: BOTELHO FILHO, F.B. Org. Agricultura Familiar e 
desenvolvimento territorial: contribuições ao debate. Brasília, Centro de Estudos Avançados Multidisciplinares. Núcleo de Estudos Avançados. V.5, n17, 2005, p. 131-139. BRASIL. Política Nacional de Agricultura Familiar. Disponível em http:// www.planalto.gov.br/ccivil_03/_ato2004-2006/2006/lei/111326.htm. Acesso em 01 mar 2020.

BUAINAIN, A. M. Agricultura familiar, agroecologia e desenvolvimento sustentável: questões para o debate. Brasília: IICA, 2006.

BUAINAIN, A. M., SALVADORI, D. Emprego e trabalho na agricultura brasileira. IICA, Brasília, DF (Brasil), 2009.

BUAINAIN, A. M., ALVES, E., SILVEIRA, J. M. D.; NAVARRO, Z. Sete teses sobre o mundo rural brasileiro. Revista de política agrícola, v. 22, n. 2, p. 105-121, 2013.

CAMARANO, A. A.; ABRAMOVAY, R. Exxodo rural, envelhecimento e masculinização no Brasil: panorama dos últimos 50 anos. IPEA, Rio de Janeiro, 1999. CAMARGO, R. A. L. de; OLIVEIRA, J. T. A. de. Agricultura familiar, multifuncionalidade da agricultura e ruralidade: interfaces de uma realidade complexa. Ciência Rural, v. 42, n. 9, p. 1707-1714, 2012.

CAMPANHOLA, C.; GRAZIANO DA SILVA, J. O novo rural brasileiro: uma análise nacional e regional. Jaguariúna, SP: Embrapa, 2000.

DE JANVRY, Alain. The agrarian question and reformism in Latin America.

Baltimore: Johns Hopkins University Press, 1981.

DELGADO, G. C.; BERGAMASCO, S. M. P. P (orgs). Agricultura familiar brasileira: desafios e perspectivas de futuro. Brasília: Ministério do Desenvolvimento Agrário, 2017. DOTTO, F. Fatores que influenciam a permanência dos jovens na agricultura familiar, no estado de Mato Grosso do Sul. 2011. Dissertação (Mestrado em Desenvolvimento Local) - Universidade Católica Dom Bosco, Campo Grande. Disponível em: https://site.ucdb.br/public/md-dissertacoes/8201-fatores-que-influenciam-apermanencia-dos-jovens-na-agricultura-familiar-no-estado-de-mato-grosso-do-sul.pdf. Acesso em 01 mar 2020. EMBRAPA, EMPRESA BRASILEIRA DE PESQUISA AGROPECUÁRIA Políticas públicas para agricultura familiar. Disponível em: https://www.embrapa.br/temaagricultura-familiar/politicas-publicas. Acesso em 15 jul 2021.

ELESBÃO, I. O espaço rural brasileiro em transformação. Finisterra, v. 42, n. 84, 2007. GRAZIANO DA SILVA, J., BALSADI, O. V., BOLLIGER, F. P., BORIN, M. R., PARO, M. R. Meio Rural Paulista: muito além do agrícola e do agrário. São Paulo em perspectiva. São Paulo, Fundação SEADE, v.10, n.2. p.60-72, 1996.

GRAZIANO DA SILVA, J. O novo rural brasileiro. Nova Economia, [S. l.], v. 7, n. 1, 1997. Disponível em:

https://revistas.face.ufmg.br/index.php/novaeconomia/article/view/2253. Acesso em: 3 jun 2021.

GRISA, C.; SCHNEIDER, S. Políticas públicas de desenvolvimento rural no Brasil / Organizadores Catia Grisa [e] Sergio Schneider. - Porto Alegre: Editora da UFRGS, 2015. $624 \mathrm{p}$.

IBGE - Instituto Brasileiro de Geografia e Estatística - Censos Demográficos.

Disponível em:

http://www.ibge.gov.br/home/estatistica/populacao/censo2010/default.shtm.

IPARDES - Instituto Paranaense de Desenvolvimento Econômico e Social. Leituras

Regionais, Curitiba, 2004. 
KAGEYAMA, Angela. As múltiplas fontes de renda das famílias agrícolas brasileiras. Agricultura em São Paulo, São Paulo, v. 48, n. 2, p. 57-69, 2001. MAIA, A. G.; BUAINAIN, A. M. O novo mapa da população rural brasileira. Confins, Paris, n. 25, p. 1-26, 2015.

MARQUES, Z.S. Os intelectuais "contemporâneos" e o debate atual sobre o êxodo rural no Brasil: uma abordagem sociológica. Trabalho de conclusão de curso (graduação) - Universidade Federal da Fronteira Sul, Curso de Licenciatura em Ciências Sociais, Erechim, RS, 2014

NIEDERLE, P. A. Afinal, que inclusão produtiva? A contribuição dos novos mercados alimentares. Delgado, G. C., Bergamasco, S. M. P. P. (orgs.). Agricultura familiar brasileira: desafios e perspectivas de futuro. Brasília: Ministério do Desenvolvimento Agrário, 2017. p. 168-196, 2017.

PASSINI, J.J. Agroindústria familiar, desenvolvimento rural e sustentabilidade. Toledo, PR, 2020. Tese apresentada ao Programa de Pós-graduação em Desenvolvimento Regional e Agronegócio - Doutorado, da Universidade Estadual do Oeste do Paraná - UNIOESTE. PEREHOUSKEI, N.; JACINTO, J. M.; MENDES, C. M. O rural e o urbano: contribuições para a compreensão da relação do espaço rural e do espaço urbano. Revista Percurso, v. 4, n. 2, p. 173-191, 2012. PNAD - PESQUISA NACIONAL POR AMOSTRA DE DOMICÍLIOS. Principais resultados. Disponível em: https://www.ibge.gov.br/estatisticas/sociais/populacao/9127pesquisa-nacional-por-amostra-de-domicilios.html?=\&t=destaques. Acesso em: 05 ago 2020.

SACCO DOS ANJOS, F.; CALDAS, N. V. Cambios demográficos em el Brasil meridional: la masculinización, el envejecimiento y la desagrarización de la población rural. In: Perspectivas Sociales - Social Perspectives, revista de la Universidad Autónoma de Nuevo León y The University of Texas at Austin, México, v. 5, nº 2, otoño/Fall, p. 71$111,2003$.

SAKAMOTO, C.; MAIA, A. G. Os impactos das mudanças na estrutura das famílias sobre a distribuição de renda: uma comparação entre áreas urbanas e rurais no Brasil. In: Anais do $51^{\circ}$ Congresso da Sociedade Brasileira de Economia, Administração e Sociologia Rural. 2013.

SCHNEIDER, S., CONTERATO, M. A., KOPPE, L. R., SILVA, C. D. A pluriatividade e as condições de vida dos agricultores familiares do Rio Grande do Sul. A diversidade da agricultura familiar. Porto Alegre: Editora da UFRGS, p. 137-164, 2006.

SCHNEIDER, S. Reflexões Sobre Diversidade e Diversificação da Agricultura, Formas Familiares e Desenvolvimento Rural. RURIS-Revista do Centro de Estudos RuraisUNICAMP, v. 4, n. 1, 2010.

Teoria social, agricultura familiar e pluriatividade. Revista Brasileira de Ciências Sociais. São Paulo: v.18, nº51, p.99-122, fev. 2003.

SCHNEIDER, S.; CASSOL, A. Diversidade e heterogeneidade da agricultura familiar no Brasil e algumas implicações para políticas públicas. Cadernos de Ciência \& Tecnologia, v. 31, n. 2, p. 227-263, 2014.

STROPASOLAS, V. L. O valor (do) casamento na agricultura familiar. Revista Estudos Feministas, v. 12, n. 1, p. 253-267, 2004.

TELLES, T.S.; COSTA, G V.D.; BACCHI, M.D.; LAURENTI, A. C. Evolução da população rural ocupada nas Grandes Regiões do Brasil entre 2001 e 2009. INTERAÇÕES, Campo Grande, MS, v. 18, n. 1, p. 17-26, jan./mar. 2017. 
WANDERLEY, M. D. N. B. Agricultura familiar e campesinato: rupturas e continuidade. Estudos sociedade e agricultura, 2003.

WANDERLEY, M. D. N. B. O agricultor familiar no Brasil: um ator social da construção do futuro. Agricultura familiar camponesa na construção do futuro. Paulo Petersen (org.) - Rio de Janeiro: AS-PTA, 2009. 